\title{
Annales Geophysicae
}

ISSN: 0992-7689 (printed version)

ISSN: 1432-0576 (electronic version)

Abstract Volume 12 Iss ue 2/3 (1994) pp 188-194

\section{The effects of ionospheric 'phase mixing' on a distributed driven shear Alfvén ulf pulsation'}

\author{
I. Krauklis, D. Orr
}

Department of Physics, University of York, Heslington, York YO1 5DD, UK

Received: 18 January 1993/Revised: 1 October 1993/Accepted: 12 October 1993

Abstract. A numerical simulation study of the ultra-low frequency (ULF) H-component magnetic field at the Earth's surface arising from a perturbation ionospheric Hall current has been developed. The Hall current system is driven by field-aligned currents (FACs) associated with shear Alfvén field line resonances (FLRs) driven by fast mode global cavity oscillations. The ionospheric phase mixing of the Hall current manifests itself in a number of ways in the ground field, these are: (i) Smoothing the spectral maxima of the ground signal: (ii) Loss in clarity of the harmonic structure of the spectra: (iii) A small increase in the damping rate of the ULF wave at the resonance latitude and (iv) small localised minimum in the spectra at the resonance latitude.

Correspondence to: D. Orr

Article not available online

Last change: October 3, 1997

helpdesk.link@springer.de

(C) Springer Berlin Heidelberg 1994 